\title{
Benchmark, Relative Return, and Asset Pricing
}

\author{
Claude Bergeron \\ School of Business Administration, Teluq University, Quebec, Canada
}

Claude Bergeron, École des sciences de l'administration, Université TÉLUQ,

455, rue du Parvis, Québec (Québec), Canada, G1K 9H6.

claude.bergeron@teluq.ca

\begin{abstract}
In this note, we develop a simple asset pricing model using the relative return to a benchmark. The model makes no assumption on free-risk securities, equilibrium conditions, utility functions, diffusion processes, probability distributions, or return generating processes. Our main result indicates that the asset's expected return is equal to the expected return of the lowest-risk asset, plus a risk premium directly proportional to the covariance between the asset's excess return and the benchmark factor. This suggests that an asset pricing model can be built without restrictive assumptions. This also suggests that the classic CAPM can be viewed as a special case of our benchmark model.
\end{abstract}

Keywords: Asset pricing, Benchmark, Relative return

JEL Classification Codes: G11, G12

\section{Introduction}

There are many extension models following the capital asset pricing model (CAPM) of Sharpe (1964) and Lintner (1965).

In this note, we develop a simple asset pricing model using the relative return to a benchmark.

The use of a benchmark portfolio for the valuation of assets represents a growing field of research in the mathematical finance literature. This benchmark approach was developed in a continuous-time framework by Platen (2006), and Platen and Heath (2006). In this set-up, the CAPM follows without the use of expected utility functions, equilibrium assumptions, or arbitrage restrictions. Along this line, many models confirm the popularity of the benchmark approach. Examples include Karatzas and Kardaras (2007), Platen and Rendek (2012), Du and Platen (2016), and Curchiero et al. (2019). 
However, the above benchmark approach requires the following assumptions: (1) the economy is limited to special markets with continuous security prices, (2) the trading uncertainty is expressed by independent standard Wiener processes, and (3) the savings account is in net zero supply. Our model makes none of these restrictive assumptions. Moreover, our model makes no restriction on free-risk securities, equilibrium (and arbitrage) conditions, utility functions, diffusion processes, probability distributions, or return generating processes. It considers a standard discrete-time framework, and its central assumption simply supposes that investors estimate the expected relative return to a benchmark.

Our main result indicates that the asset's expected return is equal to the expected return of the lowest-risk asset (or portfolio), plus a risk premium directly proportional to the covariance between the asset's excess return and the benchmark factor. This suggests that the classic CAPM can be viewed as a special case of our benchmark model.

In this sense, the main contributions of this paper can be summarized as follows. First, this paper demonstrates that we can characterize the risk-return relationship without restrictive assumptions (or under very weak assumptions). Second, it allows us to obtain similar results to the continuous benchmark approach, in an easier mathematical framework. Moreover, it allows us to avoid three restrictive assumptions (mentioned above) required by the benchmark approach (for asset valuation).

In Section 2, we expose our assumptions, build our framework, and derive our main results. In Section 3, we conclude.

\section{The model}

In this section, we develop our extension model. We first present the unrestrictive assumptions. Next, we derive the risk-return relationship using the relative return to a benchmark. Then we show that the classic CAPM can be viewed as a special case of our model. Thereafter, we focus on the lowest-risk asset and benchmark index.

\section{The assumptions}

By definition, the link between the Absolute Return, Benchmark Return, and Relative Return, is given by

$$
1+\text { Absolute Return }=(1+\text { Benchmark Return }) \times(1+\text { Relative Return }) .
$$

Thus, we have

$$
1+\text { Relative Return }=(1+\text { Absolute Return }) /(1+\text { Benchmark Return }) .
$$


Our model is based on the definitions above, and on the following (unrestrictive) assumptions:

A1 In the economy, there are many different assets and distinct investors;

A2 Investors prefer more rather than less, and are risk averse;

A3 For each asset, investors estimate the expected relative return to the benchmark.

Assumptions A1 and A2 are very easy to accept. Assumption A3 is also easy to accept, if we recognize the importance of relative motion in modern physics, and admit the usefulness of relative returns (or active returns) in portfolio management. In fact, it is reasonable to believe that a well-informed investor (or portfolio manager) will try to compare the expected returns of an investment to a reference point. In the next subsection, we will demonstrate that these three assumptions are sufficient to characterize the relationship between the risk of an asset and its expected return.

\section{The risk-return relationship}

Given the available information at time $t$, we suppose that investor $k(k=1,2, \ldots, K)$ estimates the asset's expected relative return to the benchmark, as is shown below:

$$
1+\mu_{i t k}=E_{t k}\left[\left(1+\tilde{R}_{i, t+1}^{k}\right) /\left(1+\tilde{R}_{b, t+1}^{k}\right)\right]
$$

where $\tilde{R}_{i, t+1}^{k}$ is the return of asset $i(i=1,2, \ldots, N)$ at time $t+1$, for investor $k, \tilde{R}_{b, t+1}^{k}$ is the return of the benchmark portfolio $b$, at time $t+1$, for investor $k$, and $\mu_{i t k}$ is the corresponding expected relative return. ${ }^{1}$ If we put the $(K x N)$ values of $\mu_{i t k}$ in order from lowest to highest, we can identify the associated median $\left(\bar{\mu}_{t}\right)$. We define the median investor as the one who estimates this median value. Thus, for the median investor, denoted by the letter $d$, we have

$$
1+\mu_{i t d}=E_{t d}\left[\left(1+\tilde{R}_{i, t+1}^{d}\right) /\left(1+\tilde{R}_{b, t+1}^{d}\right)\right] .
$$

In order to simplify the notation, we can ignore the letter $d$, and write

$$
1+\mu_{i t}=E_{t}\left[\left(1+\tilde{R}_{i, t+1}\right) /\left(1+\tilde{R}_{b, t+1}\right)\right]
$$

For the lowest-risk asset (or portfolio) identified by $l$, we also have

\footnotetext{
${ }^{1}$ In this manuscript, the tilde $(\sim)$ indicates a random variable. Operators $E_{t}, V_{t}$, and $\operatorname{Cov}_{t}$ refer respectively to mathematical expectations, variance and covariance, where index $t$ implies that we consider the available information at time $t$ (index $k$ refers to investor $k$ ).
} 


$$
1+\mu_{l t}=E_{t}\left[\left(1+\tilde{R}_{l, t+1}\right) /\left(1+\tilde{R}_{b, t+1}\right)\right]
$$

Equation (2) minus (3), indicates that

$$
\phi_{i t}=E_{t}\left[\left(\tilde{R}_{i, t+1}-\tilde{R}_{l, t+1}\right) /\left(1+\tilde{R}_{b, t+1}\right)\right] \text {, }
$$

with $\phi_{i t} \equiv \mu_{i t}-\mu_{l t}$. Using a compact formulation, we can express

$$
\phi_{i t}=E_{t}\left[\tilde{F}_{t+1} \tilde{r}_{i, t+1}\right] \text {, }
$$

where $\widetilde{F}_{t+1} \equiv\left(1+\tilde{R}_{b, t+1}\right)^{-1}$ represents the benchmark factor at time $t+1$, and $\tilde{r}_{i, t+1} \equiv$ $\tilde{R}_{i, t+1}-\tilde{R}_{l, t+1}$ is the excess return of asset $i$, at time $t+1$. This benchmark factor $\left(\tilde{F}_{t+1}\right)$ is similar (in its form) to the familiar stochastic discount factor (SDF). However, our benchmark factor is not based on a pure Arrow-Debreu security, and on the law of one price. In fact, equation 1 is not necessarily equal to one, and equation 4 is not necessarily equal to zero. In this regard, compared to the classic arbitrage approach, as well presented in Campbell (2018, Chapter 4), our model allows us to avoid the following restrictive assumptions: (1) there exists an unrealistic Arrow-Debreu security, and (2) arbitrage opportunities are not possible. This represents an important characteristic of our model considering, as noted by Campbell (2018, p. 112), that arbitrage opportunities are frequently visible in financial markets. From equation $4 \mathrm{~b}$ the covariance implies that

$$
\phi_{i t}=\operatorname{Cov}_{t}\left[\tilde{F}_{t+1}, \tilde{r}_{i, t+1}\right]+E_{t}\left[\tilde{F}_{t+1}\right] E_{t}\left[\tilde{r}_{i, t+1}\right]
$$

Integrating (5) in (4b) we can write

$$
1=E_{t}\left[\tilde{F}_{t+1} \tilde{r}_{i, t+1} / \phi_{i t}\right]=E_{t}\left[\tilde{F}_{t+1} \tilde{Y}_{i, t+1}\right]
$$

where $\tilde{Y}_{i, t+1} \equiv \frac{\tilde{r}_{i, t+1}}{\operatorname{Cov}\left[\tilde{F}_{t+1}, \tilde{r}_{i, t+1}\right]+E_{t}\left[\tilde{F}_{t+1}\right] E_{t}\left[\tilde{r}_{i, t+1}\right]}$. For the benchmark portfolio

$$
1=E_{t}\left[\tilde{F}_{t+1} \tilde{Y}_{b, t+1}\right]
$$

Thus, equation (6) minus (7) indicates

$$
0=E_{t}\left[\tilde{F}_{t+1}\left(\tilde{Y}_{i, t+1}-\tilde{Y}_{b, t+1}\right)\right]
$$

and the mathematical definition of covariance shows that

$$
\operatorname{Cov}_{t}\left[\tilde{F}_{t+1}, \tilde{Y}_{i, t+1}-\tilde{Y}_{b, t+1}\right]=-E_{t}\left[\tilde{F}_{t+1}\right] E_{t}\left[\tilde{Y}_{i, t+1}-\tilde{Y}_{b, t+1}\right]
$$


or after simple manipulations

$$
\operatorname{Cov}_{t}\left[\tilde{F}_{t+1}, \tilde{Y}_{i, t+1}-\tilde{Y}_{b, t+1}\right]=E_{t}\left[\tilde{F}_{t+1}\right] E_{t}\left[\tilde{Y}_{b, t+1}\right]-E_{t}\left[\tilde{F}_{t+1}\right] E_{t}\left[\tilde{Y}_{i, t+1}\right]
$$

Isolating the expected value of $\tilde{Y}_{i, t+1}$ indicates

$$
E_{t}\left[\tilde{Y}_{i, t+1}\right]=E_{t}\left[\tilde{Y}_{b, t+1}\right]-\operatorname{Cov}_{t}\left[\tilde{F}_{t+1}, \tilde{Y}_{i, t+1}-\tilde{Y}_{b, t+1}\right] / E_{t}\left[\tilde{F}_{t+1}\right]
$$

Using the properties of covariance yields

$$
\begin{aligned}
& E_{t}\left[\tilde{Y}_{i, t+1}\right]=E_{t}\left[\tilde{Y}_{b, t+1}\right]+\operatorname{Cov}_{t}\left[\tilde{F}_{t+1}, \tilde{Y}_{b, t+1}\right] / E_{t}\left[\tilde{F}_{t+1}\right]- \\
& \operatorname{Cov}_{t}\left[\tilde{F}_{t+1}, \tilde{Y}_{i, t+1}\right] / E_{t}\left[\tilde{F}_{t+1}\right] .
\end{aligned}
$$

Multiplying by the denominator of variable $\tilde{Y}_{i, t+1}$ on each side allows us to write

$$
\begin{aligned}
& E_{t}\left[\tilde{r}_{i, t+1}\right]=E_{t}\left[\tilde{Y}_{b, t+1}\right]\left(\operatorname{Cov}_{t}\left[\tilde{F}_{t+1}, \tilde{r}_{i, t+1}\right]+E_{t}\left[\tilde{F}_{t+1}\right] E_{t}\left[\tilde{r}_{i, t+1}\right]\right)+ \\
& \operatorname{Cov}_{t}\left[\tilde{F}_{t+1}, \tilde{Y}_{b, t+1}\right]\left(\operatorname{Cov}_{t}\left[\tilde{F}_{t+1}, \tilde{r}_{i, t+1}\right]+E_{t}\left[\tilde{F}_{t+1}\right] E_{t}\left[\tilde{r}_{i, t+1}\right]\right) / E_{t}\left[\tilde{F}_{t+1}\right]- \\
& \operatorname{Cov}_{t}\left[\tilde{F}_{t+1}, \tilde{r}_{i, t+1}\right] / E_{t}\left[\tilde{F}_{t+1}\right] .
\end{aligned}
$$

Developing, we can also write

$$
\begin{aligned}
& E_{t}\left[\tilde{r}_{i, t+1}\right]=E_{t}\left[\tilde{Y}_{b, t+1}\right] \operatorname{Cov}_{t}\left[\tilde{F}_{t+1}, \tilde{r}_{i, t+1}\right]+E_{t}\left[\tilde{Y}_{b, t+1}\right] E_{t}\left[\tilde{F}_{t+1}\right] E_{t}\left[\tilde{r}_{i, t+1}\right]+ \\
& \operatorname{Cov}_{t}\left[\tilde{F}_{t+1}, \tilde{Y}_{b, t+1}\right] \operatorname{Cov}_{t}\left[\tilde{F}_{t+1}, \tilde{r}_{i, t+1}\right] / E_{t}\left[\tilde{F}_{t+1}\right]+ \\
& \operatorname{Cov}_{t}\left[\tilde{F}_{t+1}, \tilde{Y}_{b, t+1}\right] E_{t}\left[\tilde{r}_{i, t+1}\right]-\operatorname{Cov}_{t}\left[\tilde{F}_{t+1}, \tilde{r}_{i, t+1}\right] / E_{t}\left[\tilde{F}_{t+1}\right]
\end{aligned}
$$

Regrouping the elements of (14) shows

$$
\begin{aligned}
& E_{t}\left[\tilde{r}_{i, t+1}\right]=\left(E_{t}\left[\tilde{Y}_{b, t+1}\right] E_{t}\left[\tilde{F}_{t+1}\right]+\operatorname{Cov}_{t}\left[\tilde{F}_{t+1}, \tilde{Y}_{b, t+1}\right]\right) E_{t}\left[\tilde{r}_{i, t+1}\right]+ \\
& \left(E_{t}\left[\tilde{Y}_{b, t+1}\right]+\operatorname{Cov}_{t}\left[\tilde{F}_{t+1}, \tilde{Y}_{b, t+1}\right] / E_{t}\left[\tilde{F}_{t+1}\right]-1 / E_{t}\left[\tilde{F}_{t+1}\right]\right) \operatorname{Cov}_{t}\left[\tilde{F}_{t+1}, \tilde{r}_{i, t+1}\right],
\end{aligned}
$$

or, if you prefer

$$
\begin{aligned}
& E_{t}\left[\tilde{r}_{i, t+1}\right]\left(1-E_{t}\left[\tilde{Y}_{b, t+1}\right] E_{t}\left[\tilde{F}_{t+1}\right]-\operatorname{Cov}_{t}\left[\tilde{F}_{t+1}, \tilde{Y}_{b, t+1}\right]\right)= \\
& \left(E_{t}\left[\tilde{Y}_{b, t+1}\right]+\left(\operatorname{Cov}_{t}\left[\tilde{F}_{t+1}, \tilde{Y}_{b, t+1}\right]-1\right) / E_{t}\left[\tilde{F}_{t+1}\right]\right) \operatorname{Cov}_{t}\left[\tilde{F}_{t+1}, \tilde{r}_{i, t+1}\right] .
\end{aligned}
$$

Isolating the expected excess return of the asset, we obtain

$$
E_{t}\left[\tilde{r}_{i, t+1}\right]=
$$




$$
\frac{E_{t}\left[\tilde{Y}_{b, t+1}\right]+\left(\operatorname{Cov}_{t}\left[\tilde{F}_{t+1}, \tilde{Y}_{b, t+1}\right]-1\right) / E_{t}\left[\tilde{F}_{t+1}\right]}{1-E_{t}\left[\tilde{Y}_{b, t+1}\right] E_{t}\left[\tilde{F}_{t+1}\right]-\operatorname{Cov}_{t}\left[\tilde{F}_{t+1}, \tilde{Y}_{b, t+1}\right]} \operatorname{Cov}_{t}\left[\tilde{F}_{t+1}, \tilde{r}_{i, t+1}\right] .
$$

Multiplying by $E_{t}\left[\tilde{F}_{t+1}\right]$ on each side of (17) implies that

$$
\begin{aligned}
& E_{t}\left[\tilde{r}_{i, t+1}\right]= \\
& \frac{E_{t}\left[\tilde{Y}_{b, t+1}\right]+\left(\operatorname{Cov}_{t}\left[\tilde{F}_{t+1}, \tilde{Y}_{b, t+1}\right]-1\right) / E_{t}\left[\tilde{F}_{t+1}\right]}{1-E_{t}\left[\tilde{Y}_{b, t+1}\right] E_{t}\left[\tilde{F}_{t+1}\right]-\operatorname{Cov}_{t}\left[\tilde{F}_{t+1}, \tilde{Y}_{b, t+1}\right]} \frac{E_{t}\left[\tilde{F}_{t+1}\right]}{E_{t}\left[\tilde{F}_{t+1}\right]} \operatorname{Cov}_{t}\left[\tilde{F}_{t+1}, \tilde{r}_{i, t+1}\right] .
\end{aligned}
$$

Taking the product of the two numerators indicates

$$
\begin{aligned}
& E_{t}\left[\tilde{r}_{i, t+1}\right]= \\
& \frac{E_{t}\left[\tilde{Y}_{b, t+1}\right] E_{t}\left[\tilde{F}_{t+1}\right]+\operatorname{Cov}_{t}\left[\tilde{F}_{t+1}, \tilde{Y}_{b, t+1}\right]-1}{1-E_{t}\left[\tilde{Y}_{b, t+1}\right] E_{t}\left[\tilde{F}_{t+1}\right]-\operatorname{Cov}_{t}\left[\tilde{F}_{t+1}, \tilde{Y}_{b, t+1}\right]} \frac{1}{E_{t}\left[\tilde{F}_{t+1}\right]} \operatorname{Cov}_{t}\left[\tilde{F}_{t+1}, \tilde{r}_{i, t+1}\right] .
\end{aligned}
$$

Therefore, after simplification, we get

$$
E_{t}\left[\tilde{r}_{i, t+1}\right]=-\left(1 / E_{t}\left[\tilde{F}_{t+1}\right]\right) \operatorname{Cov}_{t}\left[\tilde{F}_{t+1}, \tilde{r}_{i, t+1}\right]
$$

For the benchmark portfolio, we have

$$
E_{t}\left[\tilde{r}_{b, t+1}\right]=-\left(1 / E_{t}\left[\tilde{F}_{t+1}\right]\right)\left[\tilde{F}_{t+1}, \tilde{r}_{b, t+1}\right]
$$

Introducing (21) in (20) indicates

$$
E_{t}\left[\tilde{r}_{i, t+1}\right]=E_{t}\left[\tilde{r}_{b, t+1}\right] \operatorname{Cov}_{t}\left[\tilde{F}_{t+1}, \tilde{r}_{i, t+1}\right] / \operatorname{Cov}_{t}\left[\tilde{F}_{t+1}, \tilde{r}_{b, t+1}\right] .
$$

Using our definition of the excess return yields

$$
E_{t}\left[\tilde{R}_{i, t+1}\right]=E_{t}\left[\tilde{R}_{l, t+1}\right]+\left(E_{t}\left[\tilde{R}_{b, t+1}\right]-E_{t}\left[\tilde{R}_{l, t+1}\right]\right) \frac{\operatorname{Cov}_{t}\left[\tilde{F}_{t+1}, \tilde{r}_{i, t+1}\right]}{\operatorname{Cov}_{t}\left[\tilde{F}_{t+1}, \tilde{r}_{b, t+1}\right]},
$$

or to simplify the notation (as in Campbell, 2018, page 94)

$$
\begin{aligned}
& E_{t}\left[\tilde{R}_{i, t+1}\right]=E_{t}\left[\tilde{R}_{l, t+1}\right]+\lambda_{t} \mathrm{~B}_{B i t}, \\
& \lambda_{t} \equiv E_{t}\left[\tilde{R}_{b, t+1}\right]-E_{t}\left[\tilde{R}_{l, t+1}\right],
\end{aligned}
$$




$$
\mathrm{B}_{B i t} \equiv \operatorname{Cov}_{t}\left[\tilde{F}_{t+1}, \tilde{R}_{i, t+1}-\tilde{R}_{l, t+1}\right] / \operatorname{Cov}_{t}\left[\tilde{F}_{t+1}, \tilde{R}_{b, t+1}-\tilde{R}_{l, t+1}\right]
$$

Equation (24) represents our first and main result. This equation reveals that the expected return of an asset is equal to the expected return of the lowest-risk asset (or portfolio), plus a risk premium directly proportional to a benchmark beta, obtained from the covariance between the asset's excess return and the benchmark factor.

In (24), assumption A2 (risk aversion) implies that the risk premium corresponds to $\lambda_{t} \mathrm{~B}_{\text {Bit }}$. Here, we interpret the parameter lambda $\left(\lambda_{t}\right)$ as the price of risk, and the benchmark beta $\left(\mathrm{B}_{\text {Bit }}\right)$ as the quantity of risk. For the lowest-risk asset (noted by $l$ ), the excess returns equal zero, just like the quantity of risk, and (24) predicts that: $E_{t}\left[\tilde{R}_{i, t+1}\right]=$ $E_{t}\left[\tilde{R}_{l, t+1}\right]$. Also, for the benchmark portfolio (noted by $b$ ), the quantity of risk corresponds to one, and (24) now predicts that: $E_{t}\left[\tilde{R}_{i, t+1}\right]=E_{t}\left[\tilde{R}_{b, t+1}\right]$. If the quantity of risk is superior (inferior) to one, then the required return of the asset is superior (inferior) to the expected return of the benchmark portfolio.

In short, we have shown that the relationship between the risk of an asset and its expected return can be characterized using only three basic conditions, expressed by the unrestrictive assumptions above. This relationship is linear, just like the CAPM (and its most important extensions). Besides, we can take a Taylor approximation of (24) to express betas in terms of a more concrete variable and to express the linear relationship with a useful prediction closer to the classic CAPM.

\section{A special case: The classic CAPM}

According to Taylor's theorem, we can use an approximation around the point $\bar{R}_{b t}$ to obtain

$$
f\left(\tilde{R}_{b, t+1}\right) \approx f\left(\bar{R}_{b t}\right)+f^{\prime}\left(\bar{R}_{b t}\right)\left(\tilde{R}_{b, t+1}-\bar{R}_{b t}\right)
$$

where $\bar{R}_{b t} \equiv E_{t}\left[\tilde{R}_{b, t+1}\right]$. Integrating (25) into (23) suggests that the expected excess return of an asset approaches the following value:

$$
E_{t}\left[\tilde{R}_{i, t+1}\right] \approx E_{t}\left[\tilde{R}_{l, t+1}\right]+\lambda_{t} \frac{\operatorname{Cov}_{t}\left[f\left(\bar{R}_{b t}\right)+f^{\prime}\left(\bar{R}_{b t}\right)\left(\tilde{R}_{b, t+1}-\bar{R}_{b t}\right), \tilde{r}_{i, t+1}\right]}{\operatorname{Cov}_{t}\left[f\left(\bar{R}_{b t}\right)+f^{\prime}\left(\bar{R}_{b t}\right)\left(\tilde{R}_{b, t+1}-\bar{R}_{b t}\right), \tilde{r}_{b, t+1}\right]} .
$$

Using the basic properties of covariance gives

$$
E_{t}\left[\tilde{R}_{i, t+1}\right] \approx E_{t}\left[\tilde{R}_{l, t+1}\right]+\lambda_{t} \frac{\operatorname{Cov}_{t}\left[\tilde{R}_{b, t+1}, \tilde{r}_{i, t+1}\right] f^{\prime}\left(\bar{R}_{b t}\right)}{\operatorname{Cov}_{t}\left[\tilde{R}_{b, t+1}, \tilde{r}_{b, t+1}\right] f^{\prime}\left(\bar{R}_{b t}\right)}
$$

Introducing our definition of the excess return shows 


$$
E_{t}\left[\tilde{R}_{i, t+1}\right] \approx E_{t}\left[\tilde{R}_{l, t+1}\right]+\lambda_{t} \frac{\operatorname{Cov}_{t}\left[\tilde{R}_{b, t+1}, \tilde{R}_{i, t+1}-\tilde{R}_{l, t+1}\right]}{\operatorname{Cov}_{t}\left[\tilde{R}_{b, t+1}, \tilde{R}_{b, t+1}-\tilde{R}_{l, t+1}\right]}
$$

or the following relationship

$$
\begin{aligned}
& E_{t}\left[\tilde{R}_{i, t+1}\right] \approx E_{t}\left[\tilde{R}_{l, t+1}\right]+\lambda_{t} \beta_{B i t}, \\
& \beta_{B i t} \equiv \operatorname{Cov}_{t}\left[\tilde{R}_{b, t+1}, \tilde{R}_{i, t+1}-\tilde{R}_{l, t+1}\right] / \operatorname{Cov}_{t}\left[\tilde{R}_{b, t+1}, \tilde{R}_{b, t+1}-\tilde{R}_{l, t+1}\right] .
\end{aligned}
$$

Equation (29) represents our second result. This equation now reveals that the expected return of an asset is approximately equal to the expected return of the lowest-risk asset, plus a risk premium directly proportional to a benchmark beta (in lower case), obtained from the covariance between the asset's excess return and the benchmark return.

If we ignore the approximation and suppose the existence of a free-risk asset (denoted by the letter $f$ ), then we have

$$
\begin{aligned}
& E_{t}\left[\tilde{R}_{i, t+1}\right]=R_{f, t+1}+\left(E_{t}\left[\tilde{R}_{b, t+1}\right]-R_{f, t+1}\right) \beta_{B i t} \\
& \beta_{B i t}=\operatorname{Cov}_{t}\left[\tilde{R}_{b, t+1}, \tilde{R}_{i, t+1}\right] / V_{t}\left[\tilde{R}_{b, t+1}\right]
\end{aligned}
$$

Therefore, assuming that the market portfolio represents a potential reference index, we can easily see that the classic CAPM corresponds to a special case of our benchmark model.

\section{The benchmark and the lowest-risk asset}

Identification of the proper benchmark asset (for performance management) represents a crucial aspect of our model. In our setup, a benchmark is simply a standard against which the performance of a security, mutual fund, or investment manager can be measured. Benchmark types can be organized into categories by asset class (stocks, bonds, and cash) and then further categorized by capitalization ranges, sectors, countries or others. For example, in the U.S. equity market, we can take the usual $S \& P 500$ (for a large-cap benchmark). In addition, we can take the $S \& P 600$ SmallCap Index, S\&P 400 MidCap Index, $S \& P 1500$ Composite Index, or Russell 3000 Index. On the international markets, the MSCI World Index or MSCI Emerging Markets Index can be used. In fixed income, examples of benchmarks include the Barclays Capital U.S. Treasury Bond Index, Barclays Capital U.S. Aggregate Bond Index, and FTSE World Government Bond Index (WGBI).

In the same manner, there is a certain flexibility in the identification of the lowest-risk asset. This asset could be a standard Treasury bill, but in our framework, it does not have to be totally without risk. In fact, in our set-up, there are $N$ different risky assets, and we can calculate the expected return for each one. The lowest-risk asset is simply the one with 
the lowest expected return (or lowest rate), among all the $N$ assets. Moreover, the covariance between the asset's return and the benchmark is not necessarily zero. Besides, we can refer to an ordinary savings account to estimate the lowest-risk rate, as in Platen (2006) and Platen et al. (2006).

\section{Conclusion}

In this note, we used the relative return to a benchmark and three unrestrictive conditions to demonstrate that an asset's expected return is equal to the expected return of the lowestrisk asset, plus a risk premium directly proportional to the covariance between the asset's excess return and the benchmark factor. Furthermore, we showed that this linear relationship can be approximated, using Taylor's theorem. Moreover, we proposed that the classic CAPM can be viewed as a special case of our benchmark extension model. Finally, we suggested different ways to identify the benchmark index and lowest-risk rate.

\section{Acknowledgement}

I wish to thank John Y. Campbell, from Harvard University, for his very helpful comments and references.

\section{Disclosure statement}

No potential conflict of interest was reported by the author.

\section{References}

Campbell, J. Y. 2018. Financial Decisions and Markets. Princeton: University Press.

Curchiero, C., W. Schachermayer and T. K. Wong. 2019. "Covers's Universal Portfolio, Stochastic Portfolio Theory, and the Numéraire Portfolio." Mathematical Finance 29 (3): 713-803.

Karatzas, E. and C. Kardaras. 2007. "The Numéraire Portfolio in Semimartingale Financial Models." Finance and Stochastics 11 (4): 47-493.

Du, K. and E. Platen. 2016. "Benchmarked Risk Minimization." Mathematical Finance 26 (3): 617-637.

Lintner, J. 1965. "The valuation of risk assets and the selection of risky investments in stock portfolios and capital budgets." Review of Economics and Statistics 47 (1): 1337.

Platen, E. 2006. “A Benchmark Approach to Finance.” Mathematical Finance 16 (1): 131151. 
Platen, E., and D. Heath. 2006. A Benchmark Approach to Quantitative Finance. Berlin: Springer Finance, Springer.

Platen, E. and R. Rendek. 2012. "Approximating the Numéraire Portfolio by Naïve Diversification." Journal of Asset Management 13 (1): 34-59.

Sharpe, W. F. 1964. "Capital asset prices: A theory of market equilibrium under conditions of risk." The Journal of Finance, 19 (3): 425-442. 